\title{
FAKTOR-FAKTOR YANG MEMENGARUHI NIAT UMKM KULINER DALAM PEMANFAATAN LAYANAN GO-FOOD DI SURAKARTA
}

\author{
${ }^{1 *}$ Novena Hasiani Tampubolon, ${ }^{1}$ Nuning Setyowati, ${ }^{1}$ Raden Kunto Adi \\ ${ }^{1}$ Program Studi Agribisnis, Fakultas Pertanian, Universitas Sebelas Maret Surakarta \\ *e-mail: novenahasiani@gmail.com
}

\begin{abstract}
This research aims to determine factors that influence the culinary MSMEs intention to use Go-Food in Surakarta using Technology Acceptance Model (TAM) modification. Factors are perceived resources, perceived usefulness, perceived ease of use, attitude towards using, and relative advantage. The basic research method is the descriptive method. The method of location determination is purposive. The method of sample determination is purposive sampling with many samples of 60 respondents. Data collection tools using questionnaires. The data analysis method is Structural Equation Modeling (SEM). Data analysis tools using Partial Least Square (PLS) with SmartPLS 3.0. software. The research results show that perceived resources have a positive effect on perceived usefulness and perceived ease of use, perceived usefulness and perceived ease of use have positive effects on attitude towards using, perceived usefulness and perceived ease of use have positive effects on relative advantage, attitude towards using and relative advantage have positive effects on behavior intention to use Go-Food in Surakarta.
\end{abstract}

Keywords: Culinary MSMEs, Go-Food, Modified Technology Acceptance Model, Structural Equation Modeling

\section{PENDAHULUAN}

Salah satu sektor perekonomian yang potensial dan memiliki peranan penting dalam perekonomian di Indonesia adalah Usaha Mikro Kecil dan Menengah (UMKM). Menurut Nuryanti (2013), UMKM merupakan sektor usaha yang memberikan kontribusi besar terhadap pertumbuhan ekonomi, menciptakan peluang kerja dan meningkatkan pendapatan masyarakat. Seiring persaingan UMKM yang semakin kompetitif, maka penguasaan pasar merupakan syarat untuk meningkatkan daya saing. Salah satu faktor yang mendukung perkembangan UMKM adalah sarana teknologi, informasi dan komunikasi.

Platform digital yang dapat dimanfaatkan pelaku UMKM kuliner adalah aplikasi Go-Jek. Gojek memudahkan pelaku UMKM khususnya sektor kuliner untuk mempromosikan dan menjual produk secara cepat dan lebih mudah dengan menggunakan layanan Go-Food. Layanan Go-Food merupakan layanan pesan-antar makanan secara online (online delivery food). Layanan Go-Food menawarkan program kerjasama mitra bagi pelaku usaha kuliner di beberapa wilayah Indonesia, salah satunya adalah Kota Surakarta.

Penerimaan teknologi oleh pelaku UMKM kuliner di Surakarta dapat dianalisis dengan menggunakan modifikasi Technology Acceptance Model (TAM). Menurut Davis (1989), TAM merupakan teori sistem informasi yang menggambarkan model penerimaan dan penggunaan 
suatu sistem informasi. Davis (1989) mengembangkan TAM dengan variabel persepsi kegunaan dan persepsi kemudahan dalam penggunaan. Menurut Wu dan Wang (2005), pengguna percaya bahwa penggunaan teknologi/sistem akan meningkatkan performa pengguna dalam bekerja. Menurut Davis (1989), suatu aplikasi dianggap lebih mudah digunakan maka lebih mungkin untuk diterima oleh pengguna. Persepsi kegunaan dan persepsi kemudahan dalam penggunaan digunakan untuk memprediksi sikap dan sikap menentukan niat untuk menggunakan. Modifikasi TAM pada penelitian ini adalah dengan adanya variabel persepsi sumber daya dan keuntungan relatif. Menurut Oh et al. (2003), persepsi sumber daya merupakan kepercayaan yang timbul pada sumber daya untuk dapat menyelesaikan tugas tertentu pada waktu tertentu. Menurut Wang et al. (2008), semakin menguntungkan sebuah teknologi, maka akan semakin banyak pengguna yang akan termotivasi untuk mengadopsi teknologi tersebut. Oleh karena itu, peneliti tertarik untuk melakukan penelitian dengan tujuan menganalisis faktor-faktor yang memengaruhi niat UMKM kuliner dalam pemanfaatan layanan Go-Food di Surakarta.

\section{METODE PENELITIAN}

Metode dasar dalam penelitian ini adalah metode deskriptif dengan teknik survei. Menurut Furchan (2004), penelitian ini ditujukan untuk membuat deskripsi, gambaran atau lukisan fenomena-fenomena yang ada, yang berlangsung pada saat ini atau saat lampau secara sistematis, faktual dan akurat. Metode penentuan lokasi penelitian dilakukan secara purposive atau sengaja sesuai pertimbangan tertentu (Singarimbun dan Effendi, 2008). Kota Surakarta merupakan Kota yang memiliki jumlah restoran / rumah makan terbanyak di Provinsi Jawa Tengah (BPS, 2018). Banyaknya pelaku kuliner yang membuka usaha rumah makan di Surakarta menjadi salah satu pertimbangan dalam memilih Kota Surakarta menjadi tempat penelitian.

Sampel dalam penelitian ini ditentukan dengan teknik purposive sampling dan menggunakan teori $10 \mathrm{x}$ rule of thumb sebanyak 60 responden. Data yang digunakan adalah data primer dan data sekunder. Data primer diperoleh dari wawancara langsung dengan responden. Data sekunder diperoleh dari instansi yang terkait dengan penelitian ini. Teknik pengumpulan data dilakukan dengan observasi, wawancara dan pencatatan dengan alat pengumpulan data berupa kuesioner.

Metode analisis yang digunakan adalah Structural Equation Modeling (SEM). Penelitian ini menggunakan alat analisis data Partial Least Square (PLS) dengan software SmartPLS 3.0. 1. Model pengukuran (outer model) dievaluasi dengan dengan convergent dan discriminant validity dari indikatornya serta composite reliability untuk blok indikator (Ghozali, 2014). Jika nilai loading factor $>0,7$ dan $A V E>0,5$ maka data yang digunakan valid. Jika setiap indikator memiliki loading factor lebih tinggi untuk setiap variabel laten yang diukur dibandingkan dengan indikator untuk laten variabel lainnya maka variabel yang digunakan valid. Jika nilai composite reliability > 0,6 dan cronbach's alpha $>0,7$ data yang digunakan reliabel.

2. Model struktural (inner model) dievaluasi dengan melihat nilai koefisien determinasi $\left(\mathrm{R}^{2}\right)$ dan predictive relevance $\left(\mathrm{Q}^{2}\right)$ (Ghozali, 2014). Nilai $\mathrm{R}^{2}$ menunjukkan besarnya variabel eksogen menjelaskan variabel endogennya. Nilai koefisien determinasi dengan kriteria 0,25; 0,5; dan 0,75 menunjukkan model lemah, sedang, kuat secara berurutan (Hair et al, 2011). 
Jika nilai $\mathrm{Q}^{2}>0$ maka model mempunyai predictive relevance. Jika $\mathrm{Q}^{2}<0$ maka model kurang memiliki predictive relevance.

3. Pengujian hipotesis dilakukan dengan melihat nilai path coefficient melalui metode bootstrapping. Kriteria pengujian hipotesis adalah pada tingkat signifikansi 5\% dengan nilai $t$-statistic adalah 1,96 dan nilai $p$-value lebih kecil sama dengan 0,05 . Kriteria penerimaan atau penolakan hipotesis yaitu Ha: diterima ketika $p$-value bernilai $<0,05$ dan $t$-statistic bernilai > 1,96 sedangkan H0: ditolak ketika $p$-value bernilai > 0,05 dan $t$-statistic bernilai $<1,96$ (Ghozali, 2014).

\section{Model Penelitian}

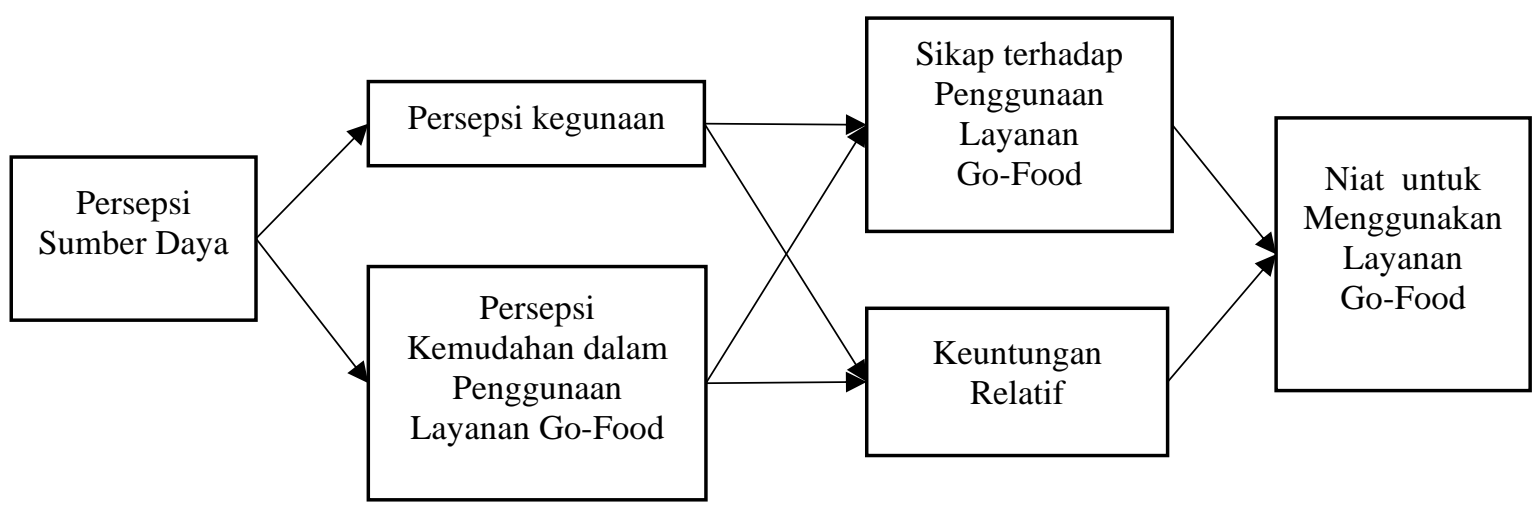

Gambar 1. Model Penelitian

\section{HASIL DAN PEMBAHASAN}

\section{Kondisi Umum Lokasi Penelitian}

Kota Surakarta merupakan salah satu kota besar yang terletak di provinsi Jawa Tengah. Wilayah Kota Surakarta merupakan dataran rendah dengan ketinggian $\pm 92 \mathrm{~m}$ dari permukaan laut. Secara geografis, Kota Surakarta terletak antara $110^{\circ} 45^{\prime} 15^{\prime \prime}$ dan $110^{\circ} 45^{\prime}$ '35" Bujur Timur danantara $7^{\circ} 36^{\prime}$ dan $7^{\circ} 56^{\prime}$ Lintang Selatan. Luas wilayah Kota Surakarta adalah 44,04 Km² dan secara administrasi terbagi menjadi lima wilayah administrasi kecamatan, yaitu Kecamatan Laweyan, Serengan, Pasar Kliwon, Jebres dan Banjarsari. Kelima kecamatan tersebut mencakup 51 kelurahan, 606 Rukun Warga (RW), 2.696 Rukun Tetangga (RT), dan 183.544 KK. Jumlah penduduk Kota Surakarta pada tahun 2018 yaitu sebesar 517.887 jiwa (BPS Surakarta, 2019).

\section{Karakteristik Responden}

Jumlah responden yang belum pernah menggunakan layanan Go-Food namun sudah mengetahui layanan Go-Food sebanyak 23 orang (36,3\%) dan responden yang sedang menggunakan layanan Go-Food sebanyak 37 orang $(61,7 \%)$. Responden dibedakan menurut kecamatan yang ada di Surakarta, yaitu Kecamatan Banjarsari, Jebres, Laweyan, Pasar Kliwon dan Serengan. Responden yang diteliti adalah pelaku usaha kuliner pada skala mikro, kecil dan menengah, dan responden didominasi oleh usaha skala mikro dengan jumlah tenaga kerja sebanyak 1-4 orang. Jenis produk yang dijual ada bermacam-macam, salah satu yang paling dominan yaitu jenis olahan daging dengan persentase $51,7 \%$. 
Analisis Data

Evaluasi Model Pengukuran (Outer Model)

Evaluasi model pengukuran dengan convergent dan discriminant validity dari indikatornya serta reliability untuk blok indikator (Ghozali, 2014). Berdasarkan pengujian convergent validity dapat diketahui bahwa semua indikator sudah memenuhi kriteria penilaian yaitu loading factor bernilai > 0,7. Hasil dari loading factor ini menunjukkan validitas yang tinggi terhadap semua indikator pada setiap konstruk. Artinya, besaran korelasi antara indikator dengan variabel latennya memiliki nilai yang tinggi.

Tabel 1. Nilai Average Variance Extracted (AVE)

\begin{tabular}{lcc}
\hline \multicolumn{1}{c}{ Variabel } & AVE & Keterangan \\
\hline Persepsi Sumber Daya & 0,870 & Valid \\
Persepsi Kegunaan & 0,845 & Valid \\
Persepsi Kemudahan dalam penggunaan & 0,852 & Valid \\
Sikap terhadap penggunaan & 0,824 & Valid \\
Keuntungan Relatif & 0,829 & Valid \\
Niat untuk menggunakan & 0,825 & Valid \\
\hline
\end{tabular}

Sumber: Data Primer, 2020

Uji convergent validity yang dilakukan selanjutnya adalah dengan melihat nilai Average Variance Extracted (AVE). Nilai AVE > 0,5 sehingga dinyatakan valid. Nilai AVE ini menunjukkan banyaknya keragaman yang dapat ditangkap oleh variabel dibandingkan dengan keragaman karena kesalahan pengukuran (Yamin et al., 2011).

Discriminant Validity dari model pengukuran dengan refleksif indikator dinilai berdasarkan cross loading pengukuran dengan konstruk. Jika korelasi konstruk dengan item pengukuran lebih besar daripada ukuran konstruk lainnya, maka hal ini menunjukkan bahwa konstruk laten memprediksi ukuran pada blok tersebut lebih baik daripada ukuran blok lainnya (Ghozali, 2014). Berdasarkan hasil penelitian ini, setiap blok indikator memiliki cross loading yang lebih tinggi untuk setiap variabel laten yang diukur dibandingkan dengan indikator untuk variabel laten lainnya. Hal ini menunjukkan bahwa setiap indikator dapat menjelaskan variabelnya dengan nilai yang lebih tinggi dari variabel lainnya sehingga terdapat kecocokan model (Sarwono, 2016).

Tabel 2. Nilai Composite Reliability dan Cronbach's Alpha

\begin{tabular}{lrrr}
\hline & Composite Reliability & Cronbach's Alpha & Keterangan \\
\hline PR & 0,964 & 0,950 & Reliabel \\
PU & 0,956 & 0,939 & Reliabel \\
PEOU & 0,958 & 0,942 & Reliabel \\
ATU & 0,949 & 0,929 & Reliabel \\
RA & 0,951 & 0,931 & Reliabel \\
BI & 0,950 & 0,929 & Reliabel \\
\hline
\end{tabular}

Sumber: Data Primer, 2020

Reliabilitas suatu instrumen dalam model pengukuran dilihat dari nilai Composite Reliability dan Cronbach's Alpha. Berdasarkan pengujian diketahui bahwa masing-masing variabel memiliki nilai Composite Reliability > 0,6 dan nilai cronbach's alpha > 0,7. Hal ini menandakan bahwa semua variabel mampu memberikan jawaban secara konsisten dan stabil. 


\section{Evaluasi Model Struktural (Inner Model)}

Evaluasi Model struktural (inner model) dilakukan dengan melihat niali R-square yang merupakan uji goodness of fit model. Semakin tinggi nilai koefisien determinasi artinya semakin baik suatu variasi variabel eksogen dapat menjelaskan variabel endogen (Ghozali, 2008). Nilai R-square penelitian ini dapat dilihat pada tabel berikut.

Tabel 3. Nilai R-square

\begin{tabular}{lrr}
\hline \multicolumn{1}{c}{ Variabel Dependen } & R-square & Kategori \\
\hline Persepsi Kegunaan & 0,759 & Kuat \\
Persepsi Kemudahan dalam Penggunaan & 0,880 & Kuat \\
Sikap terhadap penggunaan & 0,866 & Kuat \\
Keuntungan Relatif & 0,916 & Kuat \\
Niat untuk menggunakan & 0,953 & Kuat \\
\hline
\end{tabular}

Sumber: Data Primer, 2020

Hal ini menunjukkan bahwa persepsi sumber daya mampu menjelaskan konstruk persepsi kegunaan sebesar 75,9\% dan mampu menjelaskan konstruk kemudahan dalam penggunaan sebesar $88 \%$, sedangkan sisanya dijelaskan oleh variabel lain di luar model. Persepsi kegunaan dan persepsi kemudahan dalam penggunaan mampu menjelaskan konstruk sikap terhadap penggunaan sebesar 86,6\% dan mampu menjelaskan konstruk keuntungan relatif sebesar 91,6\%, sedangkan sisanya dijelaskan oleh variabel lain di luar model. Sikap terhadap penggunaan dan keuntungan relatif mampu menjelaskan konstruk niat untuk menggunakan sebesar 95,3\%, sedangkan sisanya dijelaskan oleh variabel lain di luar model.

Tabel 4. Nilai Q-Squre

\begin{tabular}{lcl}
\hline \multicolumn{1}{c}{ Variabel Dependen } & Q-square & Kategori \\
\hline Persepsi Kegunaan & 0,570 & memiliki predictive relevance \\
Persepsi Kemudahan dalam Penggunaan & 0,770 & memiliki predictive relevance \\
Sikap terhadap penggunaan & 0,743 & memiliki predictive relevance \\
Keuntungan Relatif & 0,833 & memiliki predictive relevance \\
Niat untuk menggunakan & 0,904 & memiliki predictive relevance \\
\hline
\end{tabular}

Sumber: Data Primer, 2020

Hubungan antar variabel laten juga dapat dievaluasi dengan melihat $Q$-square. $Q$-square bertujuan untuk mengukur seberapa baik nilai observasi yang dihasilkan oleh model dan juga estimasi parameternya (Ghozali, 2014). Berdasarkan pengujian diketahui bahwa persepsi kegunaan, persepsi kemudahan dalam penggunaan, sikap terhadap penggunaan, keuntungan relatif, dan niat untuk menggunakan sebesar 0,570; 0,770; 0,743; 0,833; dan 0,904. Nilai $Q$-square lebih besar dari nol berarti model memiliki predictive relevance yang tinggi.

\section{Hasil Uji Hipotesis}

Uji hipotesis dengan menggunakan software smart Partial Least Square (SmartPLS) dilakukan dengan uji statistik pada masing-masing jalur, dan hasil signifikasi dari koefisien parameter yang dihitung dengan metode bootstrapping. 
Tabel 5. Hasil Uji Hipotesis dengan metode Path Coefficient

\begin{tabular}{|c|c|c|c|c|}
\hline Hipotesis & & T-Statistics & P-Values & Keterangan \\
\hline $\mathrm{H} 1$ & Persepsi sumber daya $\rightarrow$ Persepsi Kegunaan & 35,841 & $\mathbf{0 , 0 0 0}$ & Signifikan \\
\hline $\mathrm{H} 2$ & $\begin{array}{l}\text { Persepsi sumber daya } \rightarrow \text { Persepsi kemudahan } \\
\text { dalam penggunaan }\end{array}$ & 74,468 & $\mathbf{0 , 0 0 0}$ & Signifikan \\
\hline H3a & $\begin{array}{l}\text { Persepsi Kegunaan } \rightarrow \text { Sikap terhadap } \\
\text { penggunaan }\end{array}$ & 5,372 & $\mathbf{0 , 0 0 0}$ & Signifikan \\
\hline $\mathrm{H} 3 \mathrm{~b}$ & $\begin{array}{l}\text { Kemudahan dalam penggunaan } \rightarrow \text { Sikap } \\
\text { terhadap penggunaan }\end{array}$ & 5,221 & $\mathbf{0 , 0 0 0}$ & Signifikan \\
\hline $\mathrm{H} 4 \mathrm{a}$ & Persepsi Kegunaan $\rightarrow$ Keuntungan relatif & 5,728 & $\mathbf{0 , 0 0 0}$ & Signifikan \\
\hline $\mathrm{H} 4 \mathrm{~b}$ & $\begin{array}{l}\text { Kemudahan dalam penggunaan } \\
\text { Keuntungan relatif }\end{array}$ & 4,306 & 0,000 & Signifikan \\
\hline H5a & $\begin{array}{l}\text { Sikap terhadap penggunaan } \rightarrow \text { Niat untuk } \\
\text { menggunakan }\end{array}$ & 5,035 & 0,000 & Signifikan \\
\hline $\mathrm{H} 5 \mathrm{~b}$ & $\begin{array}{l}\begin{array}{l}\text { Keuntungan } \\
\text { menggunakan }\end{array} \\
\text { relatif } \rightarrow\end{array}$ & 2,171 & $\mathbf{0 , 0 3 0}$ & Signifikan \\
\hline
\end{tabular}

Sumber: Data Primer, 2020

1) Pengaruh Persepsi Sumber Daya Terhadap Persepsi Kegunaan Layanan Go-Food di Surakarta

Berdasarkan hasil analisis dapat diketahui bahwa variabel persepsi sumber daya terhadap persepsi kegunaan memiliki nilai p-value sebesar $0,000(<0,05)$ dan nilai $t$-statistic sebesar 35,841 (> 1,96). Hal ini menunjukkan bahwa hipotesis 1 diterima, yaitu variabel persepsi sumber daya secara signifikan berpengaruh positif terhadap persepsi kegunaan layanan Go-Food di Surakarta. Artinya, semakin tinggi kepemilikan sumber daya yang memadai maka semakin tinggi persepsi kegunaan layanan Go-Food di Surakarta. Hasil penelitian ini sejalan dengan penelitian Mathieson et al. (2001) dan Wang et al. (2006). yang membuktikan Sumber daya finansial, hardware, software, waktu serta keterampilan merupakan hal yang diperlukan bagi pelaku UMKM kuliner dalam menggunakan layanan Go-Food.

2) Pengaruh Persepsi Sumber Daya Terhadap Persepsi Kemudahan dalam Penggunaan

Berdasarkan hasil analisis dapat diketahui bahwa variabel persepsi sumber daya terhadap persepsi kemudahan dalam penggunaan memiliki nilai $p$-value sebesar 0,000 $(<0,05)$ dan nilai $t$-statistic sebesar 74,468 (> 1,96). Hal ini menunjukkan bahwa hipotesis 2 diterima, yaitu variabel persepsi sumber daya secara signifikan berpengaruh positif terhadap persepsi kemudahan dalam penggunaan. Artinya, semakin tinggi kepemilikan sumber daya yang memadai maka semakin tinggi persepsi kemudahan dalam penggunaan layanan Go-Food di Surakarta. Hal ini sejalan dengan penelitian yang dilakukan oleh Mathieson et al. (2001) dan Oh et al. (2003) yang menunjukkan bahwa persepsi sumber daya berpengaruh positif terhadap persepsi kemudahan dalam penggunaan. Sebagian besar pelaku UMKM kuliner menilai bahwa dengan adanya sumber daya yang dimiliki dapat memberikan kemudahan dan kepraktisan dalam menggunakan layanan Go-Food.

3) a) Pengaruh Persepsi Kegunaan Terhadap Sikap Penggunaan

Berdasarkan hasil analisis dapat diketahui bahwa variabel persepsi kegunaan terhadap sikap penggunaan memiliki nilai p-value sebesar $0,000(<0,05)$ dan nilai t-statistic sebesar 5,372 (> 1,96). Hal ini menunjukkan bahwa hipotesis 3a diterima, yaitu variabel persepsi kegunaan secara signifikan berpengaruh positif 
terhadap sikap penggunaan. Artinya, semakin tinggi persepsi kegunaan seperti layanan Go-Food yang dapat membantu meningkatkan kinerja, produktivitas dan efektivitas pelaku UMKM kuliner maka semakin positif sikap penggunaan layanan Go-Food di Surakarta. Hal ini sejalan dengan penelitian yang dilakukan oleh Mathieson et al. (2001) dan Sivo et al. (2018) yang menunjukkan bahwa persepsi kegunaan berpengaruh positif terhadap sikap penggunaan. Berdasarkan penelitian ini, pelaku UMKM kuliner menilai bahwa layanan Go-Food dapat membantu dalam meningkatkan kinerja dan performa dalam menjalankan usaha.

b) Pengaruh Persepsi Kemudahan dalam penggunaan Terhadap Sikap Penggunaan

Berdasarkan hasil analisis dapat diketahui bahwa variabel persepsi kemudahan dalam penggunaan terhadap sikap penggunaan memiliki nilai $p$-value sebesar $0,000(<0,05)$ dan nilai t-statistic sebesar 5,221 $(>1,96)$. Hal ini menunjukkan bahwa hipotesis 3b diterima, yaitu variabel persepsi kemudahan dalam penggunaan secara signifikan berpengaruh positif terhadap sikap penggunaan. Artinya, semakin tinggi persepsi kemudahan dalam penggunaan yang dirasakan pelaku UMKM kuliner maka semakin positif sikap penggunaan layanan Go-Food di Surakarta. Hal ini sejalan dengan penelitian Venkatesh (2000), Yoon dan Kim (2006), Wang et al. (2006) yang menunjukkan bahwa persepsi kemudahan dalam penggunaan berpengaruh positif terhadap sikap penggunaan. Berdasarkan penelitian ini, pelaku UMKM kuliner menilai bahwa layanan Go-Food dapat mengurangi usaha besar dalam memasarkan makanannya dan memberikan kepraktisan dalam menjalankan usahanya. Pelaku UMKM kuliner menilai bahwa cara menggunakan layanan Go-Food dapat dengan mudah dipahami dengan tampilan aplikasinya yang sederhana.

4) a) Pengaruh Persepsi Kegunaan Terhadap Keuntungan Relatif

Berdasarkan hasil analisis dapat diketahui bahwa variabel persepsi kegunaan terhadap keuntungan relatif memiliki nilai $p$-value sebesar $0,000(<0,05)$ dan nilai $t$-statistic sebesar 5,728 (> 1,96). Hal ini menunjukkan bahwa hipotesis 4a diterima, yaitu variabel persepsi kegunaan secara signifikan berpengaruh positif terhadap keuntungan relatif. Artinya, semakin tinggi persepsi kegunaan maka semakin tinggi keuntungan relatif layanan Go-Food di Surakarta. Hal ini sejalan dengan penelitian yang dilakukan oleh Yudhistira dan Sushandoyo (2018) yang menunjukkan bahwa persepsi kegunaan berpengaruh positif terhadap keuntungan relatif. Berdasarkan penelitian ini, pelaku UMKM menilai bahwa dengan adanya peningkatan kinerja saat menggunakan layanan Go-Food dapat meningkatkan frekuensi dan volume pesanan (order) makanannya. Peningkatan pesanan akan menyebabkan omzet dan keuntungan dapat meningkat juga

b) Pengaruh Persepsi Kemudahan dalam penggunaan Terhadap Keuntungan Relatif

Berdasarkan hasil analisis dapat diketahui bahwa variabel persepsi kemudahan dalam penggunaan terhadap keuntungan relatif memiliki nilai $p$-value sebesar $0,000(<0,05)$ dan nilai t-statistic sebesar 4,306 (> 1,96). Hal ini menunjukkan bahwa hipotesis $4 \mathbf{b}$ diterima, yaitu variabel persepsi kemudahan dalam penggunaan secara signifikan berpengaruh positif terhadap keuntungan relatif. Artinya, semakin tinggi persepsi kemudahan dalam penggunaan yang 
dirasakan pelaku UMKM kuliner maka semakin tinggi keuntungan relatif layanan Go-Food di Surakarta. Hal ini sejalan dengan penelitian Yudhistira dan Sushandoyo (2018) yang menunjukkan bahwa persepsi kemudahan dalam penggunaan berpengaruh positif terhadap keuntungan relatif. Pelaku UMKM kuliner dapat menambah pelanggannya, memperluas jaringan pemasaran, dan dapat menekan biaya promosi.

5) a) Pengaruh Sikap Penggunaan Terhadap Niat untuk menggunakan

Berdasarkan hasil analisis dapat diketahui bahwa variabel sikap penggunaan terhadap niat untuk menggunakan memiliki nilai $p$-value sebesar $0,000(<0,05)$ dan nilai $t$-statistic sebesar 5,035 (> 1,96). Hal ini menunjukkan bahwa hipotesis 5a diterima, yaitu variabel sikap penggunaan secara signifikan berpengaruh positif terhadap niat untuk menggunakan. Artinya, semakin positif sikap penggunaan maka semakin tinggi niat untuk menggunakan layanan Go-Food di Surakarta. Hal ini sejalan dengan penelitian Mathieson et al. (2001) dan Sivo et al. (2018) yang menunjukkan bahwa sikap penggunaan berpengaruh positif terhadap niat untuk menggunakan. Apabila layanan Go-Food dianggap sebagai sesuatu yang bermanfaat maka responden akan memberikan respon positif terhadap layanan Go-Food, sebaliknya jika menimbulkan kerugian maka responden tidak akan menggunakannya.

b) Pengaruh Keuntungan Relatif Terhadap Niat untuk menggunakan

Berdasarkan hasil analisis dapat diketahui bahwa variabel keuntungan relatif terhadap niat untuk menggunakan memiliki nilai $p$-value sebesar $0,030(<0,05)$ dan nilai $t$-statistic sebesar 2,171 (> 1,96). Hal ini menunjukkan bahwa hipotesis 5b diterima, yaitu variabel keuntungan relatif secara signifikan berpengaruh positif terhadap niat untuk menggunakan. Artinya, semakin tinggi keuntungan relatif yang diterima maka semakin tinggi niat untuk menggunakan layanan Go-Food di Surakarta. Hal ini sejalan dengan penelitian Carter dan Campbell (2011), Yudisthira dan Sushandoyo (2018), dan Gumilang dan Hidayatullah (2018) yang menunjukkan bahwa keuntungan relatif berpengaruh positif terhadap niat untuk menggunakan.

\section{KESIMPULAN DAN SARAN}

Berdasarkan hasil penelitian ini, dapat disimpulkan bahwa persepsi sumber daya berpengaruh positif terhadap persepsi kegunaan. Persepsi sumber daya berpengaruh positif terhadap persepsi kemudahan dalam penggunaan. Sumber daya yang memadai akan membantu dan memudahkan pelaku UMKM kuliner dalam menggunakan layanan Go-Food. Persepsi kegunaan dan persepsi kemudahan dalam penggunaan berpengaruh positif terhadap sikap penggunaan layanan Go-Food. Peningkatan kinerja, produktivitas, efektivitas, dan kepraktisan dalam memasarkan produk berpengaruh terhadap sikap pelaku UMKM kuliner dalam penggunaan layanan Go-Food. Persepsi kegunaan dan persepsi kemudahan dalam penggunaan berpengaruh positif terhadap keuntungan relatif. Layanan Go-Food dapat meningkatkan pesanan, omzet dan keuntungan relatif bagi pelaku UMKM kuliner. Sikap penggunaan dan keuntungan relatif berpengaruh positif terhadap niat untuk menggunakan layanan Go-Food. Sikap positif terhadap penggunaan layanan Go-Food dan keuntungan relatif 
yang diterima oleh pelaku UMKM kuliner akan meningkatkan niat untuk menggunakan layanan Go-Food di Surakarta.

\section{DAFTAR PUSTAKA}

Carter, L., \& Campbell, R. 2011. The Impact of Trust and Relative Advantage on Internet Voting Diffusion. Journal of Theoretical and Applied Electronic Commerce Research 6 (3): $28-42$.

Davis, F. D. 1989. Perceived Usefulness, Perceived Ease of Use, dan User Acceptance of Information Technology. MIS Quarterl 13 (3): 318-340.

Davis, F.D., Bagozzi, R.P., \& Warshaw, P.R., 1989. User acceptance of computer technology: a comparison of two theoretical models. Management Science 35 (8), 982-1003.

Furchan, A. 2004. Pengantar Penelitian dalam Pendidikan. Yogyakarta: Pustaka Pelajar Offset.

Ghozali, I. 2014. Structural Equation Modeling Metode Alternatif dengan Partial Least Squares (PLS) Edisi 4. Semarang: Badan Penerbit Universitas Diponegoro.

Gumilang, I., \& Hidayatullah, D. 2018. Pengaruh Relative Advantage, Complexity, Compatibilty, Subjective Norm, dan Perceived Behavioral Control terhadap Niat Berwirausaha Online pada Lulusan Sekolah Bisnis di Bandung (Studi Kasus pada Sekolah Bisnis Manajemen Institut Teknologi Bandung dan Fakultas Ekonomi Bisnis Universitas Telkom). E-Proceeding of Management 5 (1): 360-369.

Hair Jr., J.F., Black, W.C., Babin, B.J., \& Anderson, R.E. 2011. Multivariate Data Analysis: A Global Perspective. 7th Edition. Upper Saddle River: Pearson Education.

Mathieson, K., Peacock, E., \& Chin, W.W. 2001. Extending The Technology Acceptance Model: The Influence of Perceived User Resources. Data Base, 32 (3), 86-112.

Nuryanti. 2013. Peran E-Commerce Untuk Meningkatkan Daya Saing Usaha Kecil dan Menengah (UKM). Jurnal Ekonomi 21 (4): 1-15.

Oh, S., Ahn, J., \& Kim, B. 2003. Adoption of Broadband Internet in Korea: The Role of Experience in Building Attitudes. Journal of Information Technology. 18, 267-280.

Rogers, E. M. 2003. Diffusion of innovations (5th ed). New York: The Free Press.

Sarwono, J. 2016. Membuat Skripsi, Tesis, dan Disertasi dengan PLS-SEM. Yogyakarta: Penerbit Andi

Singarimbun, M. \& Effendi, S. 2008. Metode Penelitian Survei. Jakarta: LP3ES

Sivo, S.A., Ku, C., \& Acharya, P. 2018. Understanding How University Student Perceptions of Resources Affect Technology Acceptance in Online Learning Courses. Australian Journal of Education Technology 34 (4): 72-91.

Sugiyono. 2010. Metode Penelitian Pendidikan Pendekatan Kuantitatif, Kualitatif, dan R\&D. Bandung: Alfabeta. 
Venkatesh, V., \& Davis, F. D. (2000). A theoretical extension of the technology acceptance model: Four longitudinal field studies. Management science 46 (2): 186-204.

Wang, Y., Meister, D., \& Wang, Y. 2008. Relative Advantage and Perceived Usefulness: The Adoption of Competing ICTs. Diffusion Interest Group in Information Technology Proceedings.

Wu, J., \& Wang, S. 2005. What Drives Mobile Commerce? An Empirical Evaluation of the Revised Technology Acceptance Model. Information \& Management 42 (2005) 719729.

Yamin, S., Rachmach, L.A., \& Kurniawan, H. 2011. Regresi dan Korelasi dalam Genggaman Anda. Jakarta: Salemba Empat

Yudhistira, D.S., \& Sushandoyo, D. 2018. Listening to the Voice of the Consumer: Expanding Technology AcceptanceModel for Online Transportation Context. The Asian Journal of Technology Management 11 (2): 125-136. 